\title{
AGEING STUDY OF HIGH VOLTAGE INSULATOR WITH NANO FILLERS
}

\author{
C Sunanda \\ Electrical and Electronics Engineering, RV College of Engineering, Bangalore, India \\ M N Dinesh \\ Electrical and Electronics Engineering, RV College of Engineering, Bangalore, India \\ N Vasudev \\ Additional Director (Rtd), High Voltage Division, CPRI, Bangalore, India
}

\begin{abstract}
Silicon insulating materials with Nanofillers have attracted wide interest for enhancing electrical properties. In this work the experimental results of silicone rubber[SiR]nano based polymer outdoor insulators in salt fog ageing test based on IEC 62217 are presented. The specimen made of composite material by adding $\mathrm{MgO}$ and $\mathrm{ZnO}$ as Nano filler to Silicone Rubber as the base polymer with ATH. The samples prepared consists of Virgin without any nano filler as the reference, $10 \% \mathrm{MgO}, 10 \%$ $\mathrm{ZnO}, 5 \% \mathrm{MgO}, 5 \% \mathrm{ZnO}$ nano-composite insulators. These five samples are kept in artificial salt fog chamber and aging test was conducted for a duration of $1000 \mathrm{hrs}$. Reduction of hydrophobicity, level of contamination are used as physical damaged inspection techniques were used to evaluate degree of surface deterioration. Differences in degree of surface deterioration were observed on all tested specimens just after salt fog test. It is observed that all the insulator withstood the test sample except with $10 \% \mathrm{MgO}$ which have failed after $720 \mathrm{hrs}$ of exposed to salt fog. All the samples performed well in inclined plane, tracking and erosion test. XRD on all samples before and after the test were carried out.
\end{abstract}

Keywords: Nano fillers, magnesium oxide, zinc oxid, hydrophobicity, Artificial Accelerated Salt Fog Ageing Test

Cite this Article: C Sunanda, M N Dinesh, N Vasudev, Ageing Study of High Voltage Insulator with Nano Fillers, International Journal of Electrical Engineering \& Technology, 10(5), 2019, pp. 7-16.

http://iaeme.com/Home/issue/IJEET?Volume=10\&Issue $=5$

\section{INTRODUCTION}

Electrical insulation is the backbone of all electrical apparatus and power system networks. As the level of transmission voltage is increased, lightning, dynamic over voltages and performance of the exposed insulator under polluted conditions are the most important factors which is used to determine the insulation level of the system. Insulators in transmission lines are subject to different type of pollution under different environmental conditions. Under wet 
condition due to light rain or fog and humid conditions cause flashover of polluted insulators and which leads to system outages. Hence, it is very much necessary to test the withstand capability of the insulators by artificial test methods.

It is well known that when the polluted layer of the insulator is moistened either by fog or light rain the leakage current flowing along the polluted surface of the insulator causes, drying and formation of dry bands. This disturbs the voltage distribution causing high voltages to appear across dry bands and cause partial arcs, also called scintillations. The early ageing is the main drawback of polymer insulators compared to conventional insulators. Polluted environments and those with high moisture levels in the environment, electrical discharges will develop on the surface of the insulation. In the long term, electrical discharges cause degradation of the polymer insulation in the form of electrical tracking and material erosion. To overcome the drawback of polymeric materials, micro/nano fillers are added. It is observed that, adding a few percent of nano-sized filler the properties of the original material can be drastically improved[3]. The main aim of this paper is to develop an insulator for high voltage application by adding $\mathrm{MgO}$ and $\mathrm{ZnO}$ nanofillers with $\mathrm{SiR}$ base material and experimentally studying its suitability for high voltage applications and to perform Salt fog ageing study on nano-composite based insulators under Ac excitation as per IEC 62217.

\section{SAMPLE PREPARATION}

The insulating material used for the experiment was prepared with $\mathrm{MgO}$ and $\mathrm{ZnO}$ as Nanofiller and Silicone Rubber as the base polymer[1]. The MgO preparation is easy, less time consuming and chep in production as compared to other inorganic fillers. The $\mathrm{ZnO}$ nanofillers increase the relative permittivity and also the thermal conductivity of the composite[2]. It is considered as a better reinforcement filler for improving the mechanical properties of the silicone-rubber compound. Fig 1 and Fig 2 represents a SEM image of ZnO and $\mathrm{MgO}$ nanoparticles. These images substantiate the approximate spherical shape to the nanoparticles, and some of the particles exhibit agglomeration. It was observed that the size of the nanoparticle was around 1 microns.

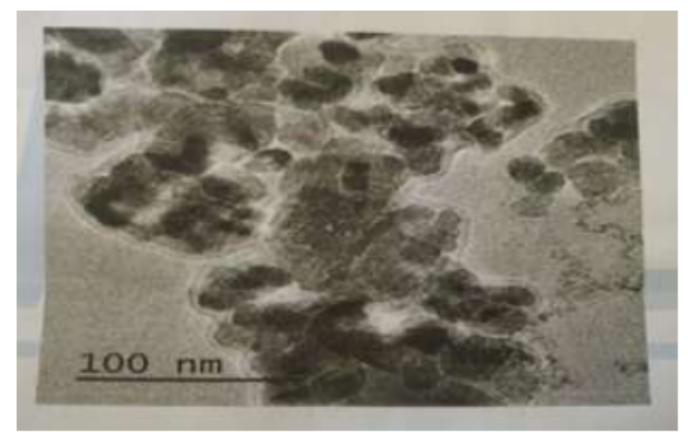

Figure 1 SEM image of $\mathrm{ZnO}$ nanoparticles.

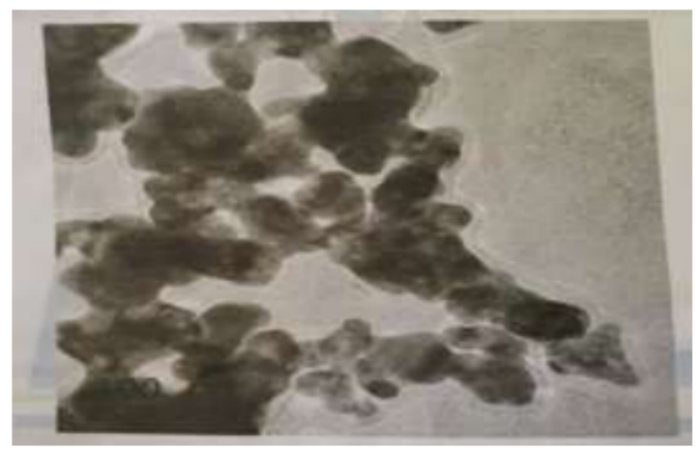

Figure $2 \mathrm{SEM}$ image of $\mathrm{MgO}$ nanoparticles. 
The fillers so prepared, were then mixed with silicone rubber to produce Nano-composites with desired concentration. For these samples, curing agents and colour are added rolled in form of sheets of $4 \mathrm{~mm}$ thickness and then cut in the required shape and size as shown in Fig 3 . These $4 \mathrm{~mm}$ sheets are used for tracking\& erosion test.

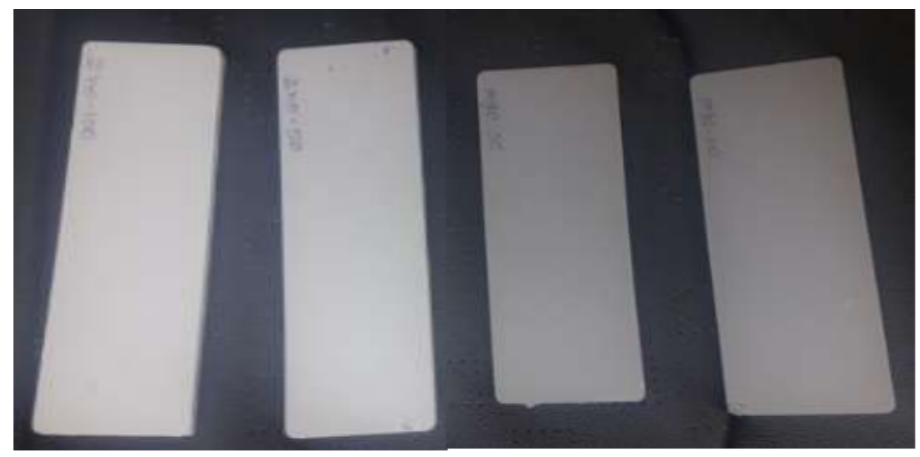

Figure 3 The samples SiR with nano fillers Composite of $4 \mathrm{~mm}$ thick

The design of Composite insulator is as shown in Fig 4 generally consist of a fibreglass rod or hollow core for mechanical strength, external weather sheds made from either silicone rubber (SiR), EPDM or EPR metal fittings for attachment .

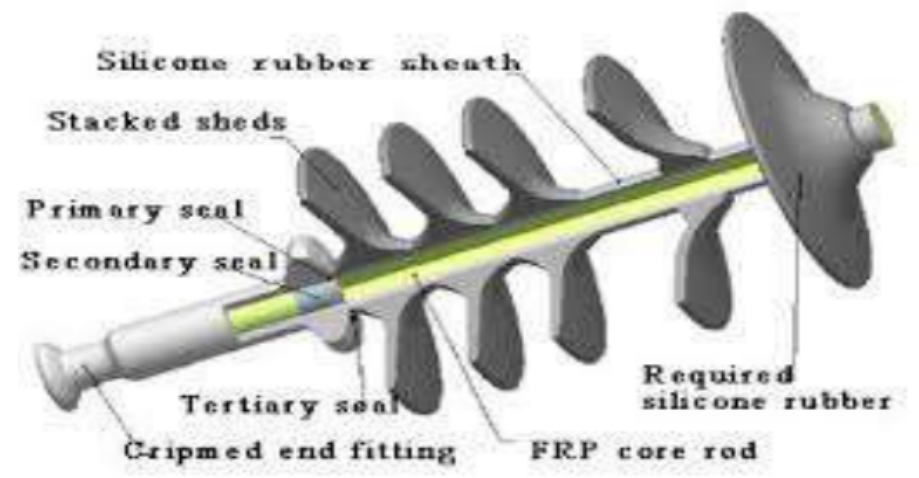

Figure 4 Design of Composite Insulator

The material was prepared by mixing the different concentration of nano fillers with $\mathrm{SiR}$ as the base polymer. The concentration of fillers were taken as percentage of the total weight of the base polymer. Total of five samples were prepared, a virgin sample without nanofiller was considered as reference. Silicon rubber based nano-composite insulators - Virgin, 5\% $\mathrm{MgO}, 10 \% \mathrm{MgO}, 5 \% \mathrm{ZnO}, 10 \% \mathrm{ZnO}$, nano-composite insulators suitable for $11 \mathrm{kV}$ were prepared as shown in Fig 5.

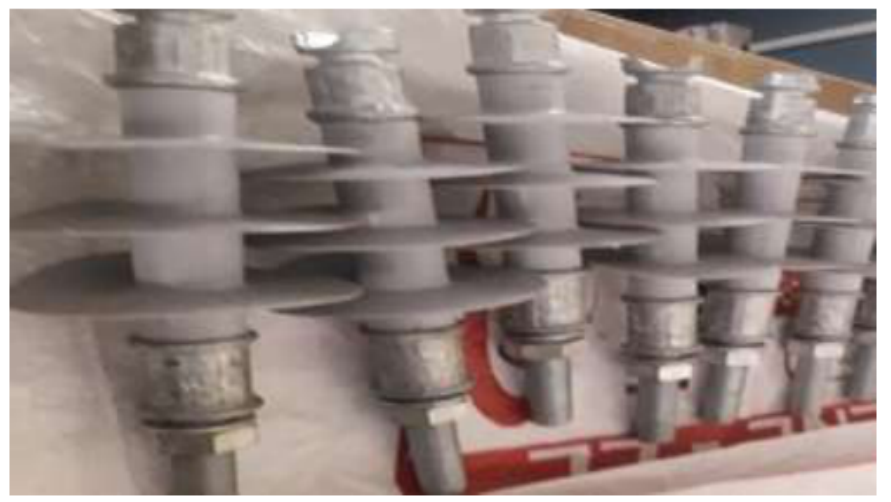

Figure 5 SR insulators with nano fillers 


\section{EXPERIMENTAL SET UP}

\subsection{Inclined plane tracking and erosion test}

Inclined plane tracking and erosion test is conducted on $4 \mathrm{~mm}$ sample sheets prepared as per table 1. All the samples are tested as per IEC 60587 .

Table 1 The details of inclined plane tracking and erosion test.

\begin{tabular}{|l|l|}
\hline Applied voltage & $4.5 \mathrm{kV}$ \\
\hline Distance between the electrode & $50 \mathrm{~mm}$ \\
\hline Test duration & $6 \mathrm{hrs}$ \\
\hline
\end{tabular}

All the samples have withstood the test of $6 \mathrm{hrs}$. Not much tracking was observed on $\mathrm{MgO}$ and virgin samples but there was some tracking erosion on $\mathrm{ZnO}$ samples. Table 2 indicates the average depth of erosion and width of erosion on $\mathrm{ZnO}$ samples.

Table 2 Average depth of erosion and width of erosion

\begin{tabular}{|c|c|c|}
\hline Samples & $\begin{array}{c}\text { Average Depth of } \\
\text { erosion }\end{array}$ & $\begin{array}{c}\text { Average width } \\
\text { of erosion }\end{array}$ \\
\hline $\mathrm{ZnO}-10 \%$ & $2.056 \mathrm{~mm}$ & $6079 \mathrm{~mm}$ \\
\hline $\mathrm{ZnO}-5 \%$ & $0.864 \mathrm{~mm}$ & $4.32 \mathrm{~mm}$ \\
\hline
\end{tabular}

HC levels from hydrophobicity test of all the five samples before and after tracking and erosion test are observed and are as shown in the table 3 . It can be seen that there is no much change in the values even after 6hrs of tracking and erosion test. From table 2 it can be concluded that average width and depth of erosion is well within the acceptable limits.

Table 3 Hydrophobicity before and after tracking and erosion tet

\begin{tabular}{|c|c|c|}
\hline Samples & $\begin{array}{c}\text { Hydrophobicity } \\
\text { before test }\end{array}$ & $\begin{array}{c}\text { Hydrophobicity } \\
\text { after the test }\end{array}$ \\
\hline $\mathrm{MgO} \mathrm{10 \%}$ & $\mathrm{HC}_{1}$ & $\mathrm{HC}_{1}$ \\
\hline $\mathrm{ZnO} 10 \%$ & $\mathrm{HC}_{2}$ & $\mathrm{HC}_{2}$ \\
\hline $\mathrm{MgO} \mathrm{5 \%}$ & $\mathrm{HC}_{1}$ & $\mathrm{HC}_{2}$ \\
\hline $\mathrm{ZnO} \mathrm{5 \%}$ & $\mathrm{HC}_{1}$ & $\mathrm{HC}_{2}$ \\
\hline Virgin & $\mathrm{HC}_{1}$ & $\mathrm{HC}_{1}$ \\
\hline
\end{tabular}

\subsection{Accelerated salt fog test}

Five insulators were prepared and are numbered as shown in Table 4 was put in an ageing chamber for Accelerated ageing salt fog test for a duration of $1000 \mathrm{hrs}$.

Table 4 Sample Insulators were numbered and then put in an ageing chamber

\begin{tabular}{|c|l|}
\hline Sample.No & \multicolumn{1}{|c|}{$\begin{array}{c}\text { Material } \\
\text { composition }\end{array}$} \\
\hline 1 & $\begin{array}{l}\text { SR with } 10 \% \text { weight } \\
\text { of } \mathrm{MgO}\end{array}$ \\
\hline 2 & $\begin{array}{l}\text { SR with } 10 \% \text { weight } \\
\text { of ZnO }\end{array}$ \\
\hline 3 & $\begin{array}{l}\text { SR with 5\% weight } \\
\text { of MgO } \\
\text { SR with 5\% weight } \\
\text { of ZnO }\end{array}$ \\
\hline 5 & Virgin SR insulator \\
\hline
\end{tabular}




\section{The Details of Insulator Design are as given below}

- Arcing distance: $190 \mathrm{~mm}(\mathrm{I})$

- Creepage distance: $346 \mathrm{~mm}(\mathrm{~A})$

- Insulators weather sheds

$\mathrm{I} / \mathrm{A}<=3$

- $\mathrm{NaCl}$ content of water $8 \pm 0.4 \mathrm{~kg} / \mathrm{m}^{3}$

- Test voltage $=\mathrm{I} / 34.6 \mathrm{kV}=10 \mathrm{kVrms}$

\section{Allowed interruption}

- for inspection $1 \mathrm{hr}$ (shall not be counted in test duration) $\rightarrow$ multiple

- For any break down $60 \mathrm{hr}$ (additional testing time of three times the duration of the interruption period shall be added) $\rightarrow$ once

Fig 6 and Fig 7 shows the test set up in an ageing chamber. Five insulators were mounted as shown. Insulators were exposed to continuous salt fog for a duration of 1000 Hours, leakage currents were monitored and tabulated.

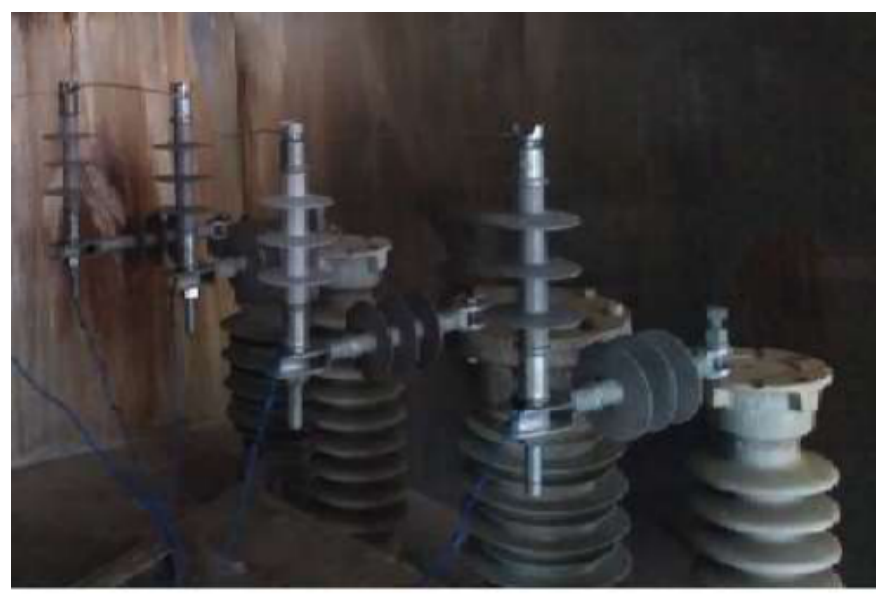

Figure 6 Ageing chamber with four insulators with nano fillers and a virgin insulator.

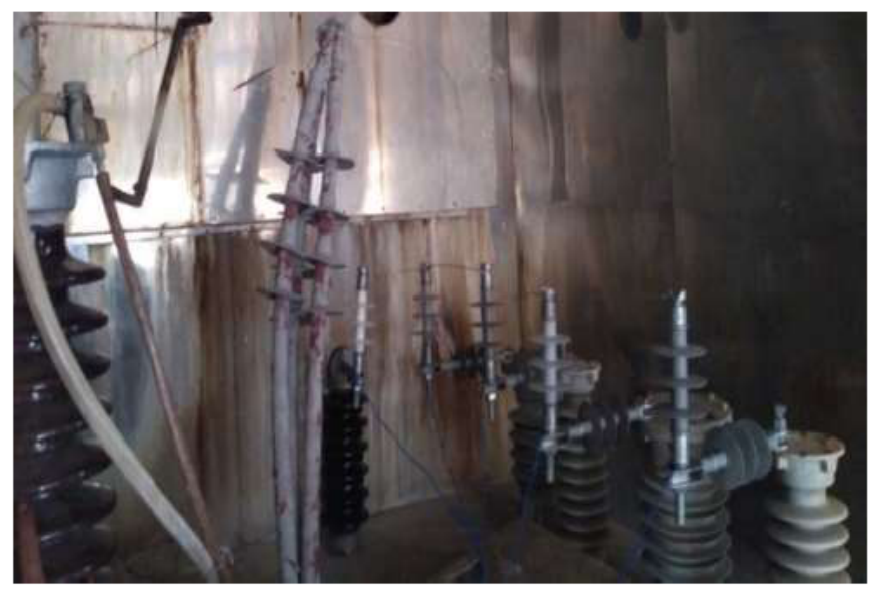

Figure 7 Another view of the ageing chamber with insulators mounted for testing. 


\section{RESULTS AND DISCUSSION}

Insulators made of HTV silicone rubber with ATH content having three different configurations, straight Shed, incline and alternate sheds, were tested continuously for $1000 \mathrm{hrs}$ in artificial salt fog chamber. Level of contamination, reduction of hydrophobicity were used as physical inspection techniques to evaluate degree of surface deterioration. Onall the tested specimens differences in degree of surface deterioration were observed after 1000 hrs of salt fog test. All these samples are also tested for tracking and erosion and hydrophobicity test .

Insulators were put in an ageing chamber and was exposed to salt fogtest $\mathrm{NaCl}$ content in water of $8 \mathrm{~kg} / \mathrm{m}^{3}$ and a voltage of $10 \mathrm{kV}$ rms was applied through out the test. Leakage currents were monitored at regular intervals and tabulated as shown in table 5.

Table 5 Leakage current after completion of 1000 hours of ageing.

\begin{tabular}{|c|l|c|}
\hline \multicolumn{2}{|c|}{ Sample } & $\begin{array}{c}\text { Average Leakage } \\
\text { current in } \boldsymbol{\mu A}\end{array}$ \\
\hline 1 & Sample with $10 \% \mathrm{MgO}$ & Falied after 720Hrs \\
\hline 2 & Sample with $10 \% \mathrm{ZnO}$ & 527.6 \\
\hline 3 & Sample with $5 \% \mathrm{MgO}$ & 543.6 \\
\hline 4 & Sample with $5 \% \mathrm{ZnO}$ & 422.2 \\
\hline 5 & Virgin sample & 352.6 \\
\hline
\end{tabular}

Plot of Leakage current with respect to the entire duration is plotted as shown in Fig 8 to Fig 12.

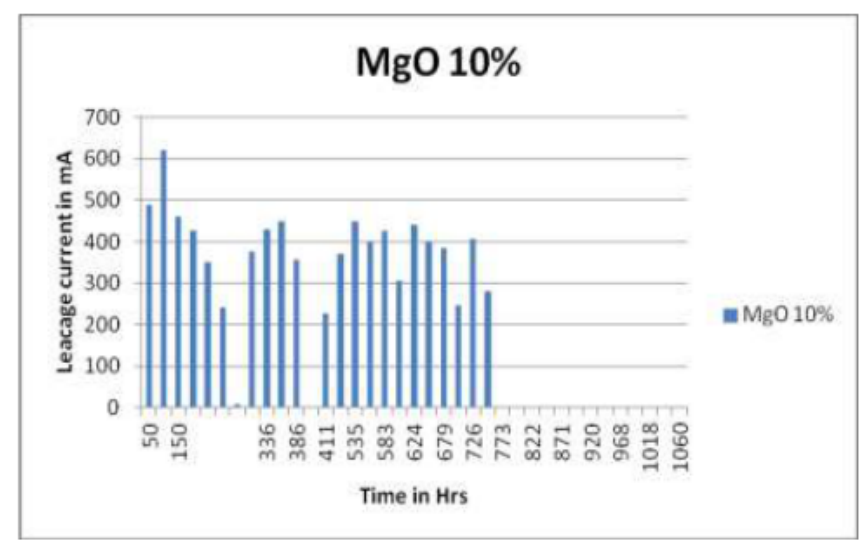

Figure 8 Plot of Leakage current with respect to the entire duration of $1000 \mathrm{Hrs}$ of sample with $\mathrm{MgO} 10 \%$.

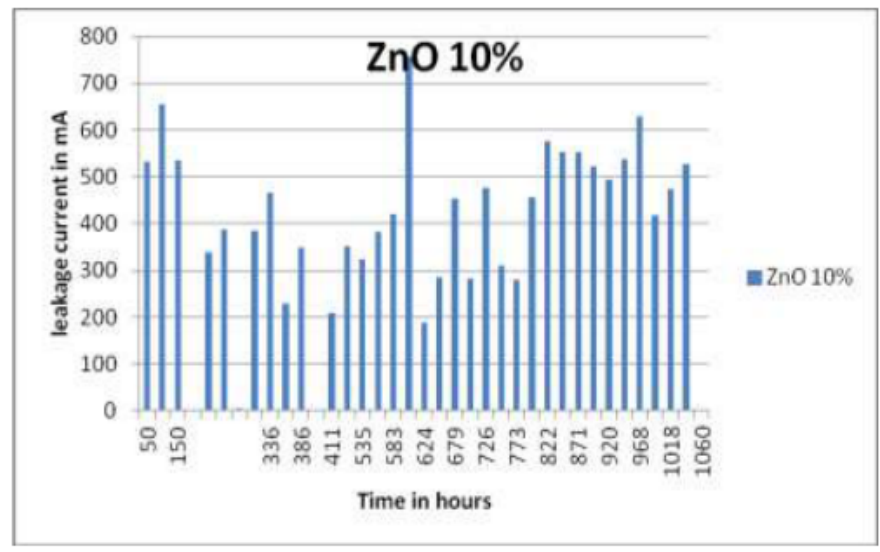

Figure 9 Plot of Leakage current with respect to the entire duration of $1000 \mathrm{Hrs}$ of sample with $\mathrm{ZnO} 10 \%$. 


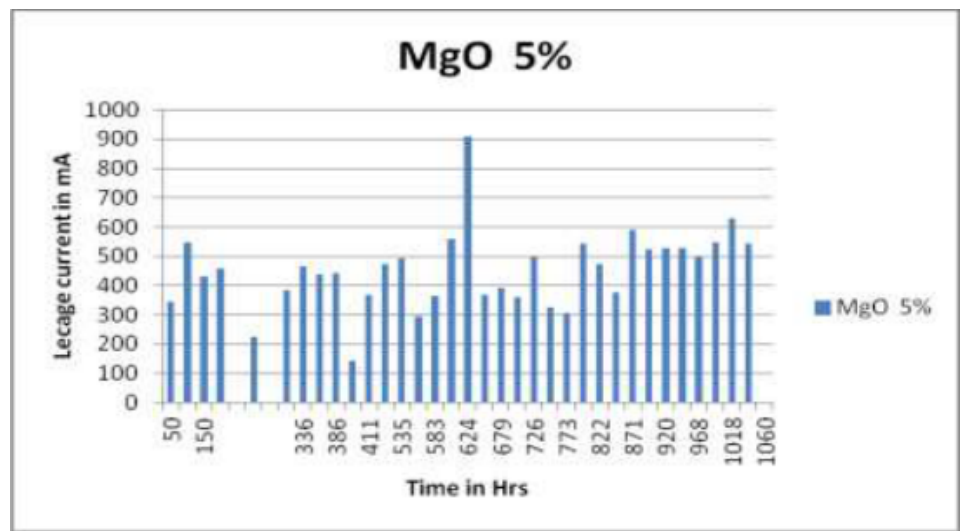

Figure 10 Plot of Leakage current with respect to the entire duration of $1000 \mathrm{Hrs}$ of sample with $\mathrm{MgO} 5 \%$.

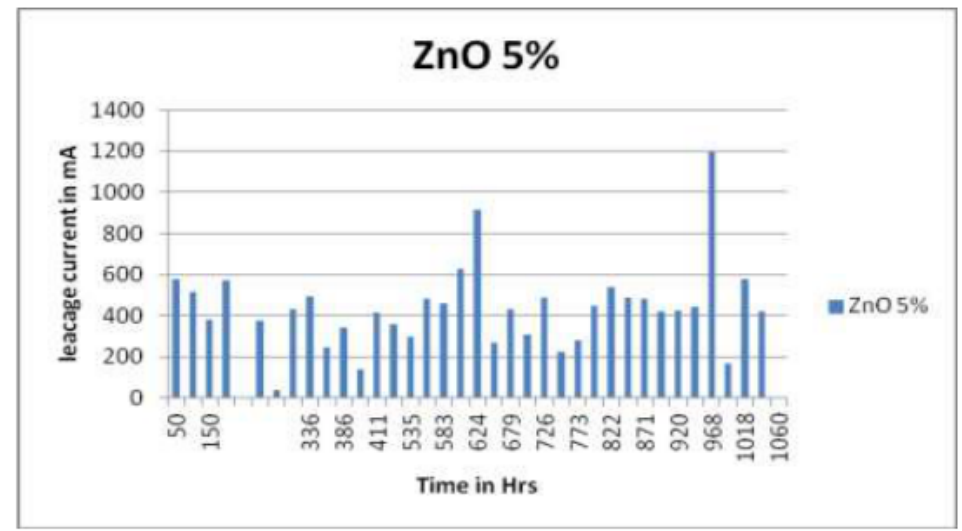

Figure 11 Plot of Leakage current with respect to the entire duration of 1000Hrs of sample with $\mathrm{ZnO} 5 \%$.

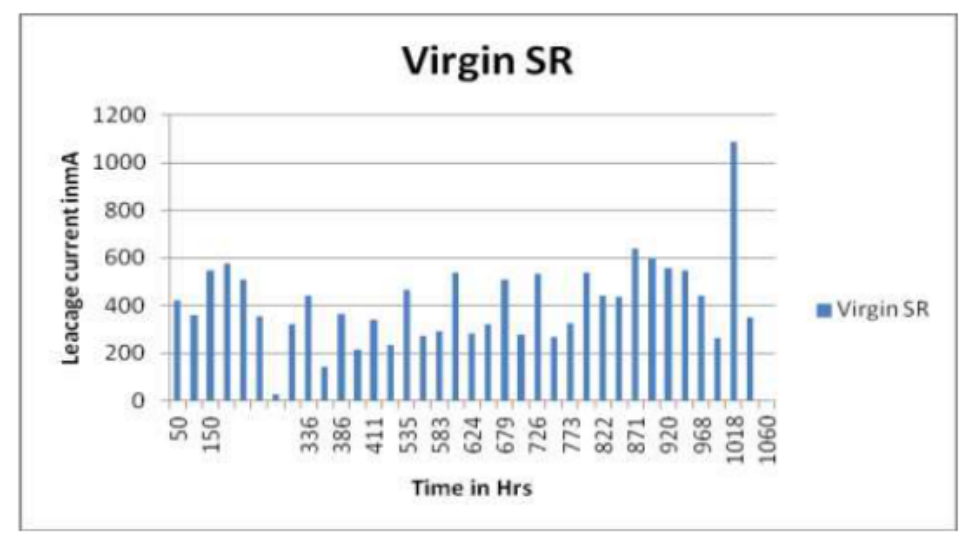

Figure 12 Plot of Leakage current with respect to the entire duration of $1000 \mathrm{Hrs}$ of virgin sample

It is observed that the average leakage current in approximately $400 \mu \mathrm{A}$ in sample 5 (virgin insulator under test) and in all other remaining insulators the leakage current during the test was around $600 \mu \mathrm{A}$.

However $\mathrm{MgO}$ with $10 \%$ of nano filler failed after 720 Hours of accelerated ageing test. That particular insulator was removed from the chamber. Degradation of all the three sheds on the damaged insulator can be observed as shown in the Fig 13. 
C Sunanda, M N Dinesh, N Vasudev

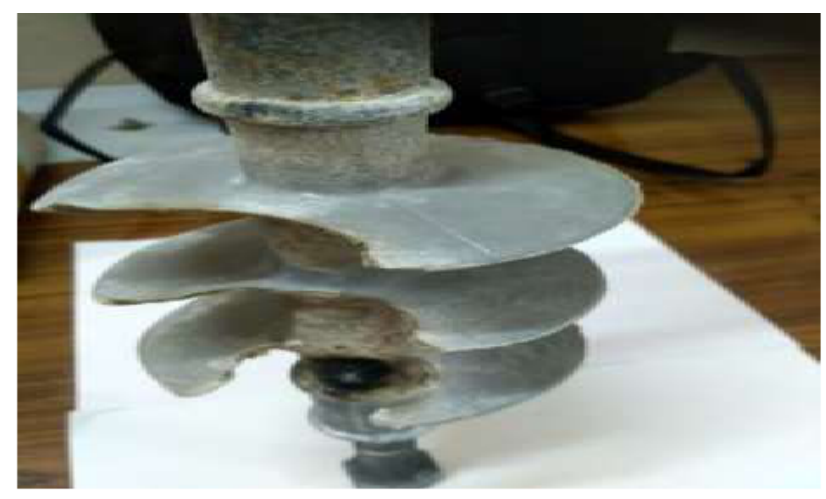

Figure 13 Damaged isolator $\mathrm{MgO}$ with 10\% nano filler after 720 Hours of accelerated ageing test.

Table 6:XRD images of all samples before and after aging.

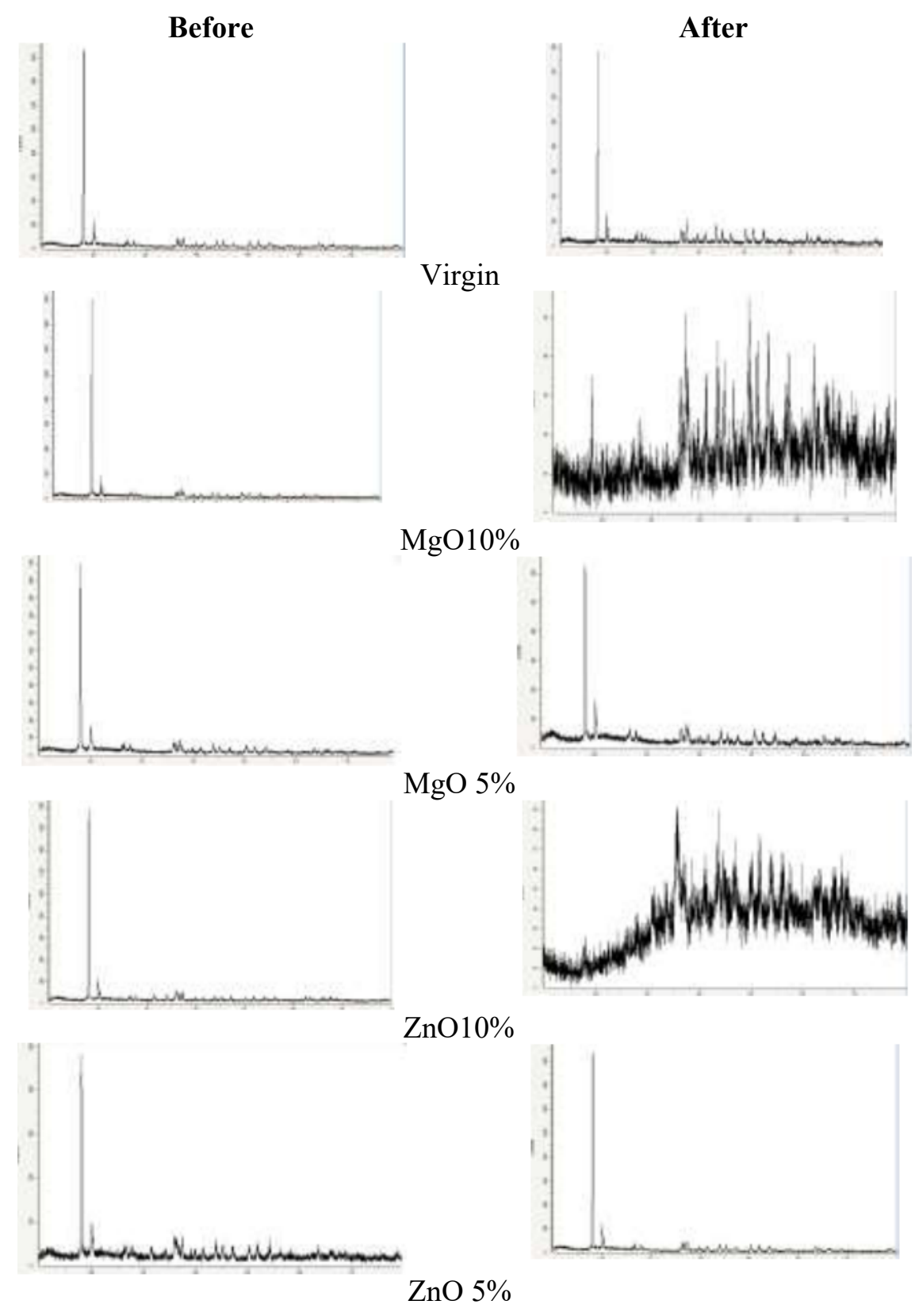


XRD analysis of all the samples before and after ageing are shown in the table 6. From the table it can be observed that after aging all the samples shows increase in crystanality, except in $10 \% \mathrm{MgO}$ and $\mathrm{ZnO}$. Samples with 10\% nano filler shows more impurity with background noise. It is also observed that insulator with $10 \% \mathrm{MgO}$ as nano filler was removed from the test due to increase in leakage current and loss of mass.

This indicates lower concentration of nano filler is preferred. Optimization has to be done considering samples with lower concentration of nano fillers.

\section{CONCLUSION}

Virgin SR insulator, insulators with $\mathrm{MgO}$ and $\mathrm{ZnO}$ as nano fillers with a concentration of 5\% and $10 \%$ were put to Accelerated ageing test for a duration of 1000 Hours. Inclined plane tracking and erosion test was carried out on 4mm thick samples as per IEC 60587.

All the five samples have passed tracking and erosion test.

Out of 5 insulators, insulator with $10 \% \mathrm{MgO}$ as nano filler has failed and was removed from test after 720 Hrs. Hydrophobicity was regained after tracking and erosion . leakage current of all the samples during $1000 \mathrm{hrs}$ of ageing test are within the limits.

From XRD analysis it can be concluded that lower concentration of nano filler performed better compared to $10 \%$ nano filler.

\section{ACKNOWLEDGEMENTS}

Material are prepared with the help of innovative silicons industry. Insulators are obtained with the help of aroser insulatorpvt ltd.

\section{REFERENCES}

[1] R.Rajendran, C. Alakumar" use of zink oxide nano articles for production of antimicrobial textiles", International Journal Engineering ,science and technology, Research department of microbiology, psg college of arts \& science coimatore, vol.2, No.1, . 202-208,2010.

[2] Agoris et al., "Emerging nanocomposite Dielectrics", Cigre Task Force report, Electra No. 226, pp. 24-31, June-2006.

[3] T.J.Lewis, "interference are the dominant feature of dielectrictrics at the nonometriclevel", IEEE Trans. Ower delivery, vol.5,no. 8,.1527-1535,1990.

[4] R.S. Gorur, E.A. Cherney and R. Hackam, "Performance of Polymeric Insulating Materials in Salt-Fog", IEEE Trans. Power Delivery, Vol. 2, No. 2, pp. 486-492, April 1987.

[5] Refat Atef Ghunem, "Using the inclined-plane test to evaluate the resistance of outdoor polymer insulating materials to electrical tracking and erosion" IEEE Electrical Insulation Magazine, Volume: 31, Issue: 5, Sept.-Oct. 2015.

[6] M.Kumosa, L.Kumosa, and D. Armentrout, "Failure analyses of non-ceramic insulators: Part II-The brittle fracture model and failure prevention," IEEE Elect. Insul. Mag.,Jul./ Aug. 2005.

[7] S.Thong-Om, W. Payakcho, J. Grasaesom, A. Oonsivilaiand B. Marungsri, "Comparison Ageing eterioration of Silicone Rubber Outdoor Polymer Insulators in Artificial Accelerated Salt Fog Ageing Test", World Academy of Science, Engineering and Technology International Journal of Materials and Metallurgical Engineering Vol:5, 
No:12, 2011, International Scholarly and Scientific Research \& Innovation 5(12) 2011 scholar.waset.org/1307-6892/6582,1062-1105.

[8] B.Venkatesulu and M. Joy Thomas," Tracking and Erosion Resistance of Nano-Filled Silicone Rubber for use in High Voltage Outdoor Insulators 16th National Power Systems Conference, 15th-17th December, 2010 ,562-566

[9] Abraiz Khattak and Muhammad Amin, "Influence of stresses and fillers on the aging behavior of polymeric insulators", Rev.Adv. Mater. Sci. 44 (2016) 194-205

[10] L. Kumosa, D. Armentrout, B. Benedikt, M. Kumosa, "An investigation of moisture and leakage currents in GRP composite hollow cylinders", IEEE Trans. Dielect. Elect.Insul., 2005. 